\title{
THE CONVEX INVERTIBLE CONE STRUCTURE OF POSITIVE REAL ODD RATIONAL MATRIX FUNCTIONS
}

\author{
S. TER HORST* AND A. NAUdÉ
}

\begin{abstract}
Positive real odd matrix functions, often referred to as positive real lossless matrix functions, play an important role in many applications in multi-port electrical systems. In this paper we present closer analogues to some of the known results for the scalar, one-port, case in the multi-port setting. Specifically, we determine necessary and sufficient conditions for the well studied partial fraction formula to represent functions in the class of positive real odd matrix functions, and explicit minimal state space realization formulas for the inverse (admittance) of a function in this class, which itself is also a positive real odd matrix function. Doing so, enables us to provide a partial analogue of the pole-zero interlacing behavior from the scalar case.
\end{abstract}

Mathematics subject classification (2010): Primary 34A09; Secondary 93B50, 93B55, 93C05, 65L80.

Keywords and phrases: Positive real odd matrix functions, lossless systems, descriptor systems, system inversion, transfer function zeros and poles.

\section{REFERENCES}

[1] B. D. O. Anderson, S. Vongpanitlerd, Networks Analysis and Synthesis, A Modern Systems Theory Approach, Prentice-Hall, New Jersey, 1973.

[2] J. A. BALL, Multidimensional circuit synthesis and multivariable dilation theory, Multidimens. Syst. Signal Process 22 (2011), 27-44.

[3] V. Belevitch, Classical Network Theory, Holden-Day, San-Francisco, 1968.

[4] T. BERGER AND T. REIS, Structural properties of positive real and reciprocal rational matrices, Proc. 21st MTNS, Groningen, The Netherlands, 2014.

[5] O. BRUNe, Synthesis of a finite two-terminal network whose driving-point impedance is a prescribed function of frequency, J. Math. and Phys. 10 (1931), 191-236.

[6] M. K. CAMLiBEl AND R. FRASCA, Extension of Kalman-Yakubovich-Popov lemma to descriptor systems, Systems Control Lett. 58 (2009), 795-803.

[7] W. CAUER, Synthesis of linear communication networks, Vols. 1 \& 2, 2nd ed., McGraw-Hill Electrical and Electronic Engineering Series, McGraw-Hill Book Co., Inc., New York-Toronto-London, 1958.

[8] W. CAUER, Theorie der linearen Wechselstromschaltungen, 2te Aufl., Akademie-Verlag, Berlin, 1954.

[9] W. CAUER, Die Verwirklichung von Wechselstromwiderständen vorgeschriebener Frequenzabhängigkeit, Archiv für Elektrotechnik 17 (1926), 355-388.

[10] D. ChU AND R. C. E. TAN, Algebraic characterizations for positive realness of descriptor systems, SIAM J. Matrix Anal. Appl. 30 (2008), 197-222.

[11] N. Cohen AND I. Lewkowicz, The Lyapunov order for real matrices, Linear Algebra Appl. 430 (2009), 1849-1866.

[12] N. COHEN AND I. LEW KOWICZ, Convex invertible cones and positive real analytic functions, Linear Algebra Appl. 425 (2007), 797-813.

[13] N. Cohen And I. Lew Kowicz, Convex invertible cones of state space systems, Math. Control Signals Systems 10 (1997), 265-286.

[14] N. Cohen AND I. Lew Kowicz, Convex invertible cones and the Lyapunov equation, Linear Algebra Appl. 250 (1997), 105-131.

[15] L. DAI, Singular control systems, Lecture Notes in Control and Information Sciences 118, SpringerVerlag, Berlin, 1989. 
[16] G. E. Dullerud and F. Paganini, A Course in Robust Control Theory: A Convex Approach, Texts in Applied Mathematics Vol. 36, Springer-Verlag, New York, 2000.

[17] R. M. Foster, A reactance theorem, Bell System Technical Journal 3 (1924), 259-267.

[18] R. W. FREUND AND F. JARRE, An extension of the positive real lemma to descriptor systems, Optim. Methods Softw. 19 (2004), 69-87.

[19] R. A. Horn and C. R. Johnson, Matrix Analysis, Cambridge U.P., Cambridge, 1985.

[20] S. TER HORST AND A. NAUdÉ, Realization formulas for involutions of matrix-valued positive real odd functions, MTNS 2020 proceedings, accepted.

[21] P. Kunkel And V. Mehrmann, Differential-algebraic equations, Analysis and numerical solution, EMS Textbooks in Mathematics, European Mathematical Society (EMS), Zürich, 2006.

[22] A. LUGER, personal communication, 2020.

[23] R. W. NewComb, Linear multiport synthesis, McGraw-Hill, 1966.

[24] N. Martins, P. C. Pellanda, And J. Rommes, Computation of transfer function dominant zeros with applications to oscillation damping control of large power systems, IEEE transactions on power systems 22 (2007), 1657-1664.

[25] T. REIS, Circuit synthesis of passive descriptor systems - a modified nodal approach, International Journal of Circuit Theory and Applications 38.1 (2010), 44-68.

[26] T. ReIs, O. RENDEL, M. VoIGT, The Kalman-Yakubovich-Popov inequality for differential-algebraic systems, Linear Algebra Applications 485 (2015), 153-193.

[27] R. L. SMith, Some interlacing properties of the Schur complement of a Hermitian matrix, Linear Algebra Applications 177 (1992), 137-144.

[28] E. D. Sontag, Mathematical control theory, Deterministic finite-dimensional systems, Second edition, Texts in Applied Mathematics 6, Springer-Verlag, New York, 1998.

[29] S. XU AND J. LAM, New positive realness conditions for uncertain discrete descriptor systems: analysis and synthesis, IEEE Trans. Circuits Syst. I. Regul. Pap. 51 (2004), 1897-1905.

[30] F. ZHANG (editor), The Schur complement and its applications, Numerical Methods and Algorithms 4, Springer-Verlag, New York, 2005.

[31] L. Zhang, J. LAM, AND S. XU, On positive realness of descriptor systems, IEEE Trans. Circuits Systems I Fund. Theory Appl. 49 (2002), 401-407.

[32] K. Zhou, J. C. Doyle And K. Glover, Robust and Optimal Control, Prentice-Hall, Upper Saddle River, NJ, 1996. 